\title{
Capitalistas industriales y Estado bajo la gestión kirchnerista. Argentina $(2003-2015)^{*}$
}

\section{Industrial Capitalists and the State During the Kirchner Administration. Argentina (2003-2015)}

\author{
Verónica Gabriela Baudino** \\ (D) https://orcid.org/0000-0001-9155-222X \\ Instituto de Investigaciones en Humanidades y Ciencias Sociales \\ Conicet-Universidad Nacional de La Plata, Argentina \\ veronicabaudino@yahoo.com.ar
}

Resumen: Este trabajo propone un recorrido por las intervenciones políticas de la Unión Industrial Argentina (UIA), la corporación más representativa de los capitales industriales que operan en Argentina, durante los gobiernos de Néstor Kirchner y Cristina Fernández de Kirchner (2003-2015). Interesa observar cómo se expresaron sus intereses económicos más inmediatos en un momento de auge del ciclo económico y de formas políticas populistas, en el que resurgió la posibilidad de articular un discurso integrador de demandas de las diferentes clases sociales. A partir del análisis de fuentes periódicas e institucionales y de indicadores económicos, concluimos que el sostenido apoyo de la entidad a la gestión kirchnerista se fundó en la convergencia, aun con contradicciones, entre las políticas económicas orientadas a la protección del mercado interno, el

* Investigación realizada como investigadora asistente de IDIHCs-ConicET.

** Doctora en Historia, Universidad de Buenos Aires. Líneas de investigación: historia política contemporánea; historia económica argentina; historia de la burguesía.

cómo citar: Baudino, V. G. (2021). Capitalistas industriales y Estado bajo la gestión kirchnerista. Argentina (2003-2015). Secuencia (110), e1755. Dor: https://doi.org/10.18234/secuencia.v0i110.1755 
aliento al consumo, las transferencias de subsidios directos e indirectos, costos laborales relativamente bajos, y las necesidades de acumulación de los capitales socios de la UIA.

Palabras clave: capitalistas industriales; Unión Industrial Argentina; Estado; populismo; postconvertibilidad.

Abstract: This paper provides an overview of the political interventions of the Argentine Industrial Union (UIA), the most representative corporation of industrial capitals operating in Argentina during the governments of Néstor Kirchner and Cristina Fernández de Kirchner (2003-2015). It is interesting to observe how their most immediate economic interests were expressed during a boom in the economic cycle and political populism, in which the possibility of articulating a discourse that incorporated demands from the various social classes resurfaced. Based on the analysis of newspaper and institutional sources and economic indicators, we conclude that the union's continued support for the Kirchner administration was based on the convergence, despite the contradictions, between the economic policies designed to protect the domestic market, the encouragement of consumption, direct and indirect subsidy transfers, relatively low labor costs, and the UIA's partners need to obtain capital.

Keywords: industrial capitalists; Argentine Industrial Union; State; populism; post convertibility.

Recibido: 4 de junio de 2019 Aceptado: 13 de abril de 2020

Publicado: 26 de abril de 2021

\section{INTRODUCCIÓN}

$\mathrm{D}$ urante los gobiernos de Néstor Kirchner y Cristina Fernández Kirchner se asistió al despliegue de un discurso marcado por la defensa de la articulación de un nuevo tipo de intervención estatal. Se sostuvo como premisa el acrecentamiento de la acción del Estado en la esfera económica a favor de la clase obrera y la pequeña burguesía, y el disciplinamiento -o 
por lo menos, la intención de conseguirlo- de los sectores concentrados de la clase capitalista. Es decir que en la postconvertibilidad ${ }^{1}$ se habría estructurado una nueva forma de relación entre el Estado y los empresarios. En este sentido, sería esperable la emergencia de fuertes contradicciones en el vínculo establecido entre el Estado y la Unión Industrial Argentina (UiA), la entidad más representativa de los industriales que operan en Argentina. Nos proponemos analizar la acción política de la entidad dado que puede revelar, además de las formas y determinaciones particulares del comportamiento del sector más importante de los capitalistas industriales que operan en Argentina, aspectos del carácter del Estado durante la última década. Es decir, estudiar el comportamiento político de un actor corporativo como la UIA, dada la centralidad económica de sus miembros, puede indicar rasgos de la burguesía que opera en argentina, en tanto formas de acción y demandas, así como el tipo de relación que el Estado establece con la clase capitalista. Ambos aspectos, en consecuencia, pueden coadyuvar a caracterizar límites y potencialidades del desarrollo del capitalismo argentino.

Exploraremos qué intereses expresó la UIA durante los gobiernos kirchneristas, cuál fue su vínculo frente a los trabajadores y el Estado. Indagaremos a su vez en las determinaciones económicas de la acción de los sujetos nucleados en la entidad. En el presente artículo se expondrán primero las cuestiones concernientes a la sociografía de la UIA, para luego dar cuenta de la acción de la entidad durante los gobiernos kirchneristas en tres subperiodos acentuando el "Conflicto del campo" como punto de inflexión.

\section{Estado del arte}

Para la mayoría de los intelectuales y políticos que han analizado su trayectoria, la UIA se comportó de forma contraria a lo que requeriría el desarrollo económico nacional. En los trabajos más influyentes se proyecta la imagen de una corporación representante de las franjas mono u oligopólicas y transnacionalizadas del capital, que tiende a "acomodarse" en cada ciclo económico persiguiendo sus intereses de corto plazo (O'Donnell, 1982). Su programa económico estaría signado por ideas liberales, entre las cuales se destacan la

${ }^{1}$ Periodo posterior a la derogación de la Ley de Convertibilidad del peso argentino, luego de su devaluación a principios de 2002. 
necesidad de la retracción del Estado de las esferas económica y social, la libre asignación de recursos a través del mercado y el otorgamiento de un papel relevante al capital multinacional (Cúneo, 1967; Freels, 1970; Ímaz, 1965), en clara oposición a la alianza encabezada por la Confederación General Económica (CGE) (Acuña, 1996; Brennan y Rougier, 2013; Niosi, 1974). Se enfatiza que la UIA, a diferencia de la CGE, es una entidad que hace escaso hincapié en políticas proindustriales (Schvarzer, 1991). Estudios más recientes han observado tendencias internas, heterogeneidad en su composición social y cambios en sus discursos y propuestas políticas (Beltrán, 2006; Coviello, 2014; Dossi, 2009; Gaggero y Wainer, 2009).

Los capitalistas integrantes de la UiA habrían constituido la alianza que pugnó por una "revancha oligárquica" mediante el establecimiento de la última dictadura militar. A juicio de quienes sostienen una mirada de la historia económica argentina centrada en la acción política, el régimen de facto habría instaurado - por medio de la intervención en la política estatal- un modelo de acumulación asentado en la valorización financiera (Azpiazu y Schorr, 2010; Basualdo, 2006). Esta novedosa forma de acumulación, hegemonizada por capitales concentrados nacionales y extranjeros, implicaba la supremacía de la valorización del capital en la esfera financiera en detrimento de la productiva. La burguesía nacional y sus "aliados", la clase obrera, serían los perdedores indiscutidos del proceso. ${ }^{2}$

El periodo kirchnerista ha sido objeto de discusiones en cuanto a si expresó o no la continuidad del modelo dominante desde 1976. ¿Cambió la base de acumulación vigente en Argentina?, ¿incentivó la primacía de la burguesía nacional, revirtiendo la de la oligarquía diversificada?

Existe cierto acuerdo -incluso entre quienes, en principio, resaltaron las diferencias- en que prevalecieron las continuidades sobre las rupturas. Aunque se parte de la idea de un Estado más autónomo respecto de los intereses inmediatos de los diferentes sectores capitalistas (Thwaites Rey, 2010), la transnacionalización de la economía y la hegemonía de los grandes capitales darían cuenta de un modelo que no pudo recrear una burguesía nacional capaz de desarrollar un proyecto de país diferente (Gaggero, Schorr y Wainer, 2014). Según señalan Castellani y Gaggero (2018), "Este rasgo estructural más cortoplacista y de reticencia inversora que caracteriza a la élite económica argentina no se alteró de modo sustantivo con el giro de modelo macroeconó-

${ }^{2}$ Para una crítica de esta teoría véase Baudino (2012); Eskenazi (2009); Fitzimons (2013). 
mico y constituye uno de los límites claros a las estrategias de desarrollo de los gobiernos progresistas" (pp. 206-207).

Un punto de vista alternativo ofrece Cantamutto (2017): entiende que el kirchnerismo implicó un nuevo orden político hegemónico desde una ruptura populista que advino luego de la crisis del neoliberalismo. Este nuevo orden se habría erigido en torno a la articulación hegemónica de un sector del bloque de poder, del cual la UIA fue integrante esencial.

Nuestro interés es aportar al conocimiento de las determinaciones económicas de la acción de los sujetos representados por la UIA en tanto es un aspecto menos explorado de la relación de los capitalistas con el kirchnerismo. Para ello consideramos necesario partir de las particularidades de la acumulación de capital en Argentina.

\section{Fundamentos teóricos y perspectivas metodológicas}

Partimos de la consideración de que la acumulación de capital constituye una unidad mundial fragmentada en espacios nacionales. Estos fragmentos, representados por los Estados nacionales como expresiones del capital social, son la forma que toma el proceso mundial de acumulación de capital (Altvater, 1976; Iñigo Carrera, 2003). En la división internacional del trabajo, Argentina ocupa el lugar de proveedora de materias primas. Dado que la productividad del trabajo de sus tierras es superior a la de los países usualmente denominados "centrales", el consumo de sus mercancías les permite a estos incrementar la plusvalía relativa que se apropian. Dichos países han propiciado el desarrollo de las relaciones capitalistas de otros como Argentina, y los límites inherentes a su conformación como proveedor de materias primas a escala internacional. Así, a fin de proveerse de mercancías producidas en condiciones que no pueden reproducir mediante el trabajo humano, el capital extranjero facilita créditos, la aplicación de tecnología y el mejoramiento de los sistemas de transporte, sin que ello redunde en el bienestar general de la población, como la historia nos ha demostrado.

Aun habiendo atravesado procesos de reconfiguración de la división internacional del trabajo y el resurgimiento de ciertos sectores industriales durante la postconvertibilidad, Argentina continúa siendo una economía nacional cuya particularidad es la producción de mercancías primarias con destino al mercado mundial. Debido a que las materias primas son mercancías 
no reproducibles por el trabajo humano, el precio de mercado se fija en el nivel de la tierra donde la productividad del trabajo es más baja. Ese pago por encima de lo "normal" constituye la renta diferencial, disputable entre capitalistas y dueños de la tierra porque no afecta la reproducción del capital agrario. En Argentina, la renta de la tierra es apropiada por sujetos distintos al terrateniente -por ejemplo, capitalistas industriales- que a través de varios mecanismos (subsidios, tipo de cambio, tasas de interés negativas) articulados mediante la acción del Estado habilitan el sostenimiento de una industria de baja productividad (Kornblihtt, Seiffer y Mussi, 2016). Dada la debilidad de sus capitales, esos capitalistas industriales, nacionales y extranjeros, requieren de la apropiación de renta de la tierra para alcanzar la tasa de ganancia media necesaria para continuar reproduciéndose (Iñigo Carrera, 2007).

Dicha determinación general de la acumulación de capital como unidad mundial, fragmentada en espacios nacionales representados por sus respectivos Estados, tiene su expresión concreta en la acción política de los sujetos. Ellos expresan en su comportamiento político el movimiento del capital. El capital es entendido aquí como la relación social que reproduce la vida en la sociedad moderna; una relación que tiene dos polos: capitalistas y obreros (Marx, 2004).

En este trabajo nos ocuparemos de un segmento de los capitalistas, aquellos nucleados en la UiA. Nos preguntamos qué es lo que la UiA expresó particularmente durante los gobiernos kirchneristas, cuál fue su posición frente a los trabajadores y qué acciones llevó adelante frente al Estado, representante del capital social, articulador de los diversos mecanismos de distribución de la renta de la tierra.

Las preguntas formuladas implican como metodología el análisis de información acerca de la UIA. Trabajamos especialmente con declaraciones públicas de los representantes de la entidad, expresiones vertidas en el ámbito interno-institucional, información publicada en periódicos y en revistas especializadas en economía y política de la época. Asimismo, recabamos detalles de las políticas económicas implementadas, dado que nuestro interés es reconstruir qué opiniones han despertado entre los capitalistas industriales. Nos inclinamos por la reconstrucción de una de las formas posibles de acción empresarial: aquella mediada por la corporación (Acuña, 1995). En este recorte, dejamos entonces en suspenso el lobby ejercido individualmente, así como otras formas cuyas marcas en las fuentes accesibles son casi nulas. Asimismo, intentamos dar cuenta tanto de las acciones dirigidas directamente al 
poder estatal cuya finalidad haya sido la implementación de políticas afines como de aquellas orientadas a generar consenso público respecto de determinada cuestión, mediante ejercicios de retórica (Wyczykier y Anigstein, 2014; Dossi, 2009).

Las principales fuentes consultadas son hemerográficas (periódicos de circulación masiva, Clarín, La Nación, Cronista Comercial), en tanto es el lugar privilegiado donde hallar información no disponible en las fuentes institucionales. No obstante, estas, en caso de estar disponibles, son ineludibles. Por tal razón, por otro lado, relevamos las Memorias y Balances. También se utilizó bibliografía especializada (Basualdo, 2006; Iñigo Carrera, 2007) y publicaciones oficiales-estatales (boletines oficiales).

Las fuentes han sido relevadas y la información útil para nuestra investigación clasificada según los temas de interés más recurrentes (tipo de cambio, salarios, subsidios, relaciones con otras corporaciones y sectores sociales) y ordenada cronológicamente. Se pusieron en juego, en primer lugar, el "análisis documental" a la hora de seleccionar el corpus de fuentes disponibles adecuadas para los propósitos de la investigación y el posterior "análisis de contenido" de las mismas (Fernández, 2002; Peña Vera y Pirela Morillo, 2007). Se analizaron los principales enunciados del discurso empresarial y se los cotejó con otras fuentes disponibles a fin de asegurar su fiabilidad.

Nuestra estrategia de análisis parte de pensar el discurso político como acción y como expresión de relaciones sociales (Marx, 2004). Consideramos que la acción particular de los sujetos como agentes voluntarios se encuentra definida por su ser social, por ser vendedores o compradores de fuerza de trabajo. La acción política de la UIA y las cámaras industriales está determinada en este sentido por garantizar la reproducción inmediata de sus capitales socios. Para tal fin, dirigen sus demandas al Estado nacional, representante del capital social ${ }^{3}$ en tanto fragmento del capital mundial. Dicho Estado nacional expresa en Argentina la especificidad de la acumulación de capital en este espacio particular.

En el presente trabajo hemos distinguido las demandas más relevantes y constantes de los capitalistas para el Estado, e intentado explicar a qué

3 "Las potencias directas de la acumulación de capital social necesitan encarnarse, entonces, en un sujeto que enfrente a los capitales individuales no sólo como portador de una conciencia y voluntad independiente de la de ellos, sino que tenga la potestad de imponer la suya directamente por sobre ellos. Este representante político directo del capital social es el Estado" (Iñigo Carrera, 2003, p. 16). 
ideas/necesidades más generales de la acumulación de capital respondieron. Es decir, cruzamos las demandas enunciadas con las particularidades de los capitales estudiados y exploramos qué necesidad de la acumulación del capital de los capitales individuales se expresó en su discurso.

\section{LA UNIÓN INDUSTRIAL ARGENTINA}

La UIA fue fundada el 7 de febrero de 1887 mediante la unificación de dos entidades: el Club Industrial Argentino y el Centro Industrial Argentino. Una asamblea compuesta por 470 socios constituyó la base para su creación.

La UIA es la entidad corporativa más representativa de la fracción industrial de la burguesía que opera en Argentina. En la mayor parte de los trabajos sobre ella se ha asumido, a partir de sus posicionamientos político-corporativos, que expresa los intereses de los capitales nacionales y extranjeros más concentrados. Su supuesta preferencia por la implementación de políticas liberales daría cuenta del tamaño de las empresas que la integran (las más grandes del país). Sin embargo, un análisis de su composición social muestra que hasta la década de 1980 estaba integrada por un núcleo reducido de grandes capitales en alianza con un vasto conjunto de capitales menores a escala nacional, todos en posiciones relegadas en el mercado mundial (Baudino, 2012).

Una mirada sobre el periodo 2003-2015 evidencia que la heterogeneidad en la composición social parece mantenerse. La dirigencia de la entidad, dividida desde finales de los años setenta en dos listas internas -el Movimiento Industrial Nacional (MIN) y el Movimiento Industrial Argentino (MIA)-, reestructuradas en 2004 luego de una crisis entre ambas y asimismo en su interior (Grimaldi, 2014), aglutina capitales de diversos tamaños y ramas.

La agrupación MIN-Industriales está integrada por un importante número de capitales pequeños (metalurgia, juguetes, calzado y textiles), así como por grandes grupos económicos (Techint y Arcor). Por su parte, MIA-Celeste y Blanca también tiene una composición heterogénea: capitales pequeños que se acumulan en la industria plástica y gráfica; grandes capitales nacionales (Ledesma, Aceitera General Deheza, SanCor, Molinos Río de la Plata y Mastellone, por ejemplo) y extranjeros (Nestlé, Coca Cola, Kraft, Quickfood, Cargill, Pepsi Cola, Dreyfus, Cervecería Quilmes), que hacen lo propio en las ramas de la industria automotriz, alimentación y agroindustria (Schteingart, 2011). 
El cuadro 1 menciona a los dirigentes de la UIA, cara visible de la entidad en el periodo estudiado.

Muchas de las empresas a las que pertenecen los dirigentes que han formado parte de la comisión directiva entre 2003 y 2015 componen el ranking de las 1000 más vendedoras en el mercado local (véase cuadro 2). La mayoría, sin embargo, no llega a ocupar los primeros 100 puestos. Lascurain, De Mendiguren, Rial y Méndez coexisten con dirigentes de capitales que no figuran en el ranking, aunque representan ramas de la industria textil y metalúrgica, muy dinámicas durante el kirchnerismo.

Se replica la alianza entre grandes capitales (nacionales y extranjeros) y pequeños, propia de otros periodos de la entidad. ¿Qué es lo que habilita que un universo heterogéneo de capitalistas se unifique en acciones políticas conjuntas desde el punto de vista económico?

Las ramas de la industria con representación en el Consejo Directivo de la UIA experimentaron un mejoramiento de su performance durante el periodo de la postconvertibilidad (véase gráfica 1). Este dato permite pensar en una acción impulsada por una expansión generalizada.

Sin embargo, el crecimiento del producto no implica que se haya modificado la competitividad de la industria que opera en Argentina. De hecho, si ponderamos a las exportaciones como indicadoras de la capacidad de cada industria para competir en el exterior, concluimos que persiste la tendencia de que las mercancías de origen industrial son muy inferiores a las de origen agropecuario (véase gráfica 2).

Se muestra que la UIA congrega a capitales que en su inmensa mayoría no utilizan al país como plataforma para una inserción competitiva en el mercado mundial. ${ }^{4}$ Inclusive los grandes capitales extranjeros como Nestlé, Coca Cola, Kraft, Quickfood, Cargill, Pepsi Cola, Dreyfus, no se instalan en Argentina con el objeto de exportar la mayor parte de su producción, sino de apropiarse de fuentes extraordinarias de ganancias. Los casos excepcionales como Arcor y Techint -capitales exportadores, competitivos a escala internacional- no parecen modificar la capacidad de acción colectiva de la entidad.

Podría objetarse el aserto a partir de la observación de que en 2002 el núcleo de capitales más concentrados fundó la Asociación de Empresarios Argentinos (AEA), compartiendo en muchos casos la doble afiliación y orien-

${ }^{4}$ La participación de las exportaciones industriales argentinas en el mercado mundial osciló $0.18 \%$. Fuente: Estimados Mensual Industrial (INDEC). 
Cuadro 1. Dirigentes de la UIA según agrupación interna

\begin{tabular}{lll} 
Agrupación & \multicolumn{1}{c}{ Dirigente } & \multicolumn{1}{c}{ Empresa/actividad } \\
\multirow{2}{*}{ Industriales } & José Ignacio de Mendiguren & Texlona \\
& Luis María Betnaza & Techint \\
& Adrián Kauffman Brea & Arcor \\
& Juan Carlos Lascurain & Royo \\
Celeste y Blanca & Héctor Méndez & Conarsa \\
& Cristiano Ratazzi & FIAT \\
& Daniel Funes de Rioja & Copal \\
& Juan Carlos Sacco & Federación Argentina de \\
& & la Industria Gráfica \\
& José Urtubey & Celulosa Argentina \\
& Miguel Acevedo & Aceitera General Deheza \\
& Luis Ureta Sáenz Peña & Peugeot \\
& Rubén Abete & Laboratorio Dallas \\
& Jorge Sorabilla & TN Platex \\
Álvaro Álvarez Gaiani & Sadia \\
& Héctor Massuh & Massuh
\end{tabular}

Fuente: elaboración propia con base en varias fuentes periodísticas e institucionales.

tando una acción progresivamente crítica respecto de las políticas económicas. Asimismo, la Coordinadora de las Industrias de Productos Alimenticios (Copal), representante de capitales agroindustriales, ha sido más propensa a diferenciarse en sus posicionamientos (lo veremos sobre todo desde 2008, durante el "conflicto del campo"). Sin embargo, más allá de los contrastes en sus posturas, la posibilidad de llevar a cabo una acción política conjunta, así como de conciliar discursos y reclamos implica necesariamente una base de intereses comunes que habilite tal comunión.

La unidad se fundamenta en que son fragmentos débiles del capital que se expresan de manera conjunta en materia de política económica. Estos capitales requieren de recursos extraordinarios para compensar su baja productividad del trabajo. Es el Estado el que interviene en las formas de transferir riquezas para posibilitar la ganancia media de los capitales. Su acción 


\section{Cuadro 2. Dirigentes de la UIA según empresa y posición en el ranking de mayores vendedores}

Nombre

Empresa

Actividad/industria

Alimentación

Alimentación

Farmacéutica

Alberto Álvarez

Saavedra

Aldo R. Espósito

Cristiano Rattazzi

Daniel Funes de Rioja

De Mendiguren

Federico Nicholson

Guillermo Gotelli

Guillermo Moretti

Héctor Massuh

Héctor Méndez

Héctor Motta

Horacio Martínez

Jorge Soravilla

José Luis Basso

\author{
Sadia (Cía. de BRF) \\ Arcor \\ Dador
}

Antonio Espósito S. A. Curtiembre

FIAT

Texlona

Ledesma

Alpargatas

Massuh

Conarsa

Grupo Motta Avícola

TN \& Platex

Basso

Automotriz

Textil

$$
\text { Santa Fe }
$$

Papel

Plástica

Avícola

Textil

Autopartes
Asesor laboral

Textil, calzado
Puesto en ranking de ventas

2003200520072009201120132015

Azúcar, papel y agroindustria

Federación de Industriales de

Presidente de Industriales Navieros

709860

$\begin{array}{lllllll}26 & 20 & 19 & 16 & 18 & 22 & 24\end{array}$

$\begin{array}{rrrrrrr} & 555 & 724 & 947 & & & \\ 171 & 74 & 25 & 20 & 11 & 26 & 53\end{array}$

$\begin{array}{lllllll}89 & 105 & 82 & 90 & 88 & 113 & 130\end{array}$

$\begin{array}{lllllll}279 & 199 & 351 & 323 & 238 & 294 & 253\end{array}$

$355 \quad 458$

954 


\begin{tabular}{|c|c|c|c|c|c|c|c|c|c|}
\hline \multirow[t]{2}{*}{ Nombre } & \multirow[t]{2}{*}{ Empresa } & \multirow[t]{2}{*}{ Actividad/industria } & \multicolumn{7}{|c|}{ Puesto en ranking de ventas } \\
\hline & & & 2003 & 2005 & 2007 & 2009 & 2011 & 2013 & 2015 \\
\hline Juan Carlos Lascurain & Royo S. A. & Tubos de acero sin costura & & & & & & & \\
\hline Juan Carlos Sacco & & $\begin{array}{l}\text { Federación Argentina de la Indus- } \\
\text { tria Gráfica }\end{array}$ & & & & & & & \\
\hline Juan Moravek & & $\begin{array}{l}\text { Presidente de la Unión Industrial } \\
\text { de la Patagonia }\end{array}$ & & & & & & & \\
\hline Luis Betnaza & Techint & Tubos sin costura, construcción & 2 & 1 & 1 & 1 & 1 & 1 & 1 \\
\hline Luis Ureta Sáenz Peña & Peugeot Argentina & Automotriz & 91 & 35 & 23 & 12 & 24 & 22 & 45 \\
\hline Miguel Acevedo & Aceitera Gral. Deheza & Aceitera & 10 & 15 & 12 & 21 & 20 & 19 & 13 \\
\hline Osvaldo Rial & Hermetal & Metalúrgica & & & & & & & \\
\hline Roberto Arano & Ingenio La Corona & Azucarera & & & & & & & \\
\hline Roberto Domenech & & Centro de Empresas Avícolas & & & & & & & \\
\hline
\end{tabular}

Fuente: elaboración propia con base en datos de la revista Mercado, varios años. 
Gráfica 1. Índice de volumen físico de la producción (2003-2014)

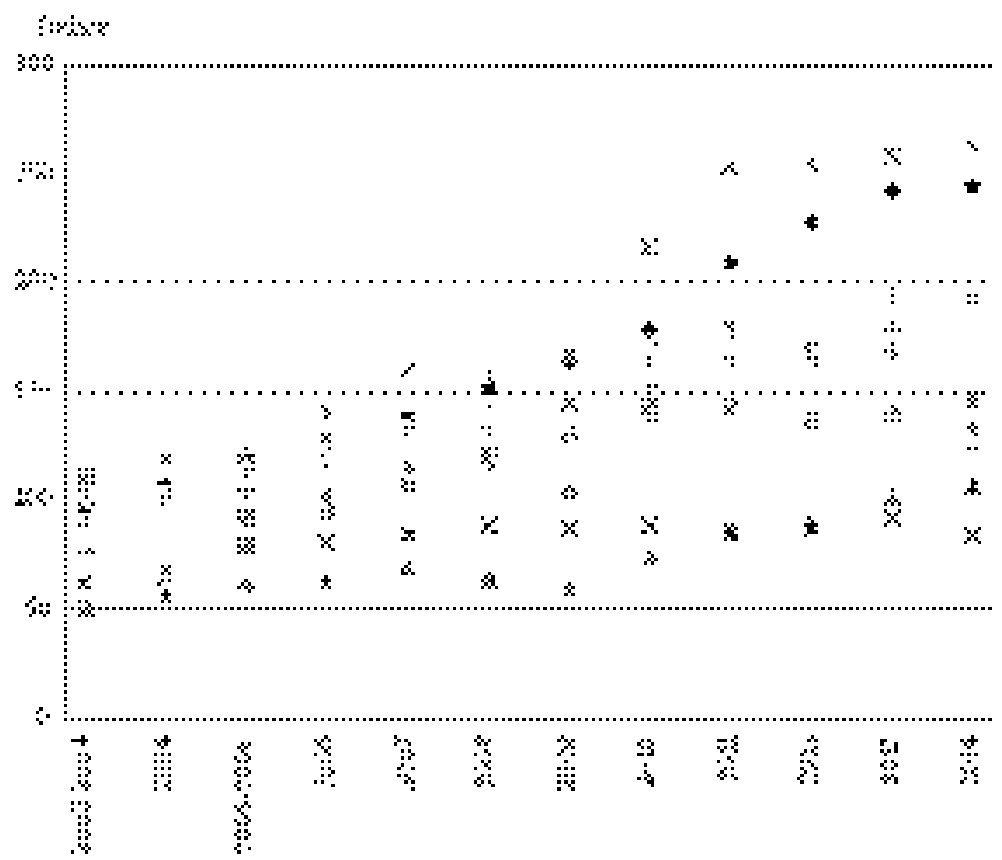

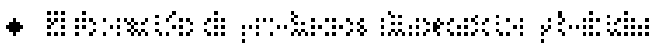

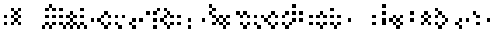

ค. :

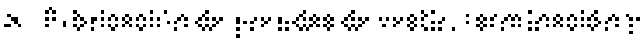

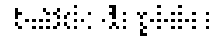

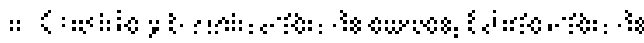

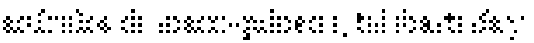

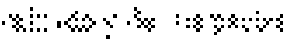

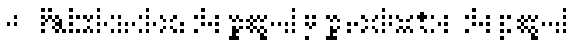

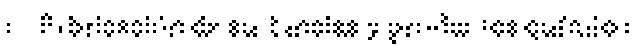
A.

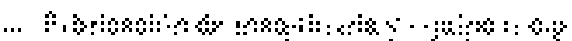

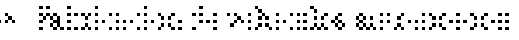

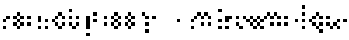

Fuente: elaboración propia con base en datos de Estimados Mensual Industrial (INDEC), varios años. 
Gráfica 2. Exportaciones por grandes rubros. Miles de uDs (2003-2015)

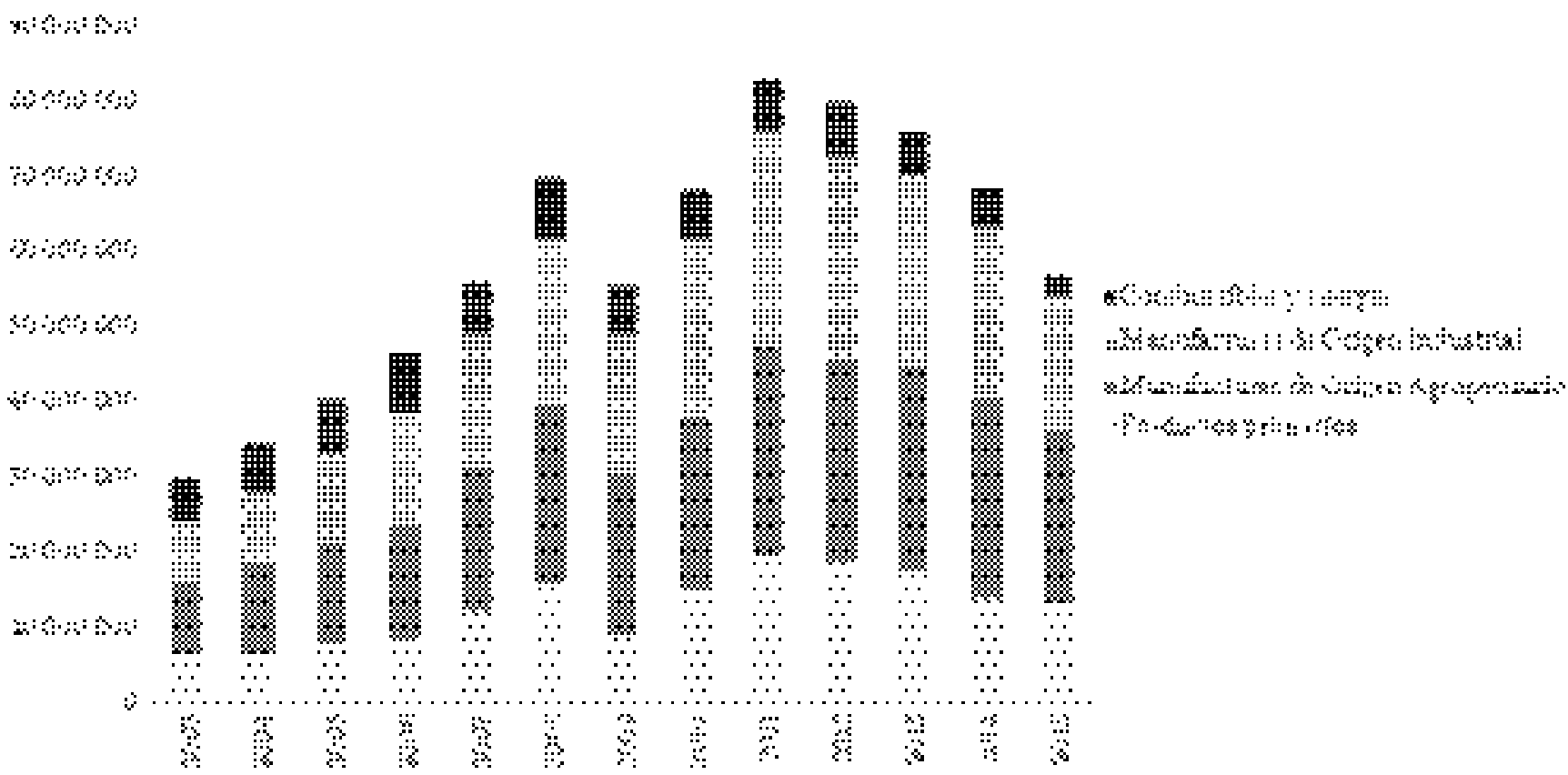

Fuente: Elaboración propia con base en datos de Estimados Mensual Industrial (INDEC). 
política se vincula así con la posibilidad de asegurarse la distribución de renta por diferentes mecanismos que disminuyan sus costos y les permita acumular en el mercado interno.

En el siguiente apartado se indaga cómo se ha comportado políticamente frente al Estado esta agrupación de capitalistas nacionales grandes y pequeños, $y$ transnacionales, durante los gobiernos kirchneristas.

\section{ACCIONES POLÍTICAS EN RELACIÓN CON LOS GOBIERNOS KIRCHNERISTAS}

\section{De cal y de arena}

El mandato de Néstor Kirchner se inició en 2003 coincidente con el aumento de los precios de las mercancías agropecuarias y, por lo tanto, de la renta diferencial, que inauguró un nuevo ciclo expansivo del capital en Argentina. Mediante la implementación de las retenciones a las exportaciones, se dio curso al crecimiento de las transferencias de riqueza desde los sectores terratenientes a capitalistas y obreros. A diferencia de los gobiernos neoliberales, la gestión kirchnerista puso en marcha un sustancial incremento del gasto público destinado tanto a gasto social como a infraestructura, tarifas de servicios subvencionadas, créditos a tasas inferiores a las de la inflación, entre otros (Porta, Santarcágelo y Schteingart, 2018). Sumado a la previa devaluación del peso, luego de años de vigencia de la ley de convertibilidad, el Estado y su régimen ahora populista ${ }^{5}$ ponía en juego mecanismos que posibilitaban la expansión de la economía -es decir, de los capitales que operaban en Argentina- incorporando además demandas de los grupos sociales que constituyeron la avanzada contra la convertibilidad (Piva, 2019).

${ }^{5}$ Entendemos por "populista" la forma política que se asume en momentos de auge del ciclo económico, que implica transferencias a los capitales individuales y mejoramiento de las condiciones de vida de la clase obrera. Por oposición, la estrategia denominada "liberal" aparece en momentos de contracción económica, recortando transferencias y en consecuencia eliminando capital sobrante. Ambos momentos se corresponden con los ciclos de renta de la tierra y endeudamiento, especificidad del capitalismo argentino (Iñigo Carrera, 2007). Para un balance de las caracterizaciones como populista y bonapartista de los gobiernos kirchenistas, véase Baudino (2017). 
La UIA apoyó la candidatura de Néstor Kirchner sosteniendo, en la voz de su dirigente Héctor Massuh, que "existen coincidencias entre los lineamientos económicos de Kirchner para el caso de llegar a la presidencia y las pretensiones de este sector empresario". ${ }^{6}$ Dichas coincidencias se mantuvieron, en lo esencial, a lo largo de la gestión del matrimonio Kirchner (Néstor Kirchner [2003-2007] y Cristina Fernández de Kirchner [2008-2015]). Expresaron en un primer momento su adhesión a la política de Roberto Lavagna al frente del Ministerio de Economía por "ordenar la economía luego de más de cuatro años de depresión económica y de la fuga de capitales y depósitos sin antecedentes en la historia económica argentina”, $y$, a su vez, por el valor del dólar: "es el principal incentivo para la reactivación y suple otros incentivos para la demanda. Es la mejor forma de apuntalar el nivel de actividad". De hecho, la UIA insistió durante toda esta primera etapa en la necesidad de mantener un dólar alto. Asumía que el tipo de cambio bajo "sería peligroso", ya que pondría en riesgo la competitividad de la industria, dado que "no sólo nos resultará imposible exportar sino que además recibiremos más importaciones". ${ }^{8}$ La centralidad del tipo de cambio para los capitalistas radicaba en que la devaluación del peso implicó la baja de los costos salariales y la protección del mercado interno, necesarias para la supervivencia de capitales con una productividad muy inferior a la media mundial, y que además, no tienen a disposición una fuerza de trabajo lo suficientemente barata para compensar esta debilidad (Iñigo Carrera, 2007).

La cancelación anticipada de la deuda con el Fondo Monetario Internacional, anunciada en diciembre de 2005 por el gobierno, dio de que hablar en el concierto de empresarios en general y en la UIA en particular. El monto a saldar era de 9500 millones de dólares a pagar con reservas del Banco Central. La entidad manifestó su acuerdo con la iniciativa y la fundamentó con varios argumentos. Sus dirigentes resaltaron la "independencia y madurez" y el fortalecimiento de la economía gracias a que los ahorros futuros podrían destinarse a otorgar créditos al sistema productivo. Asimismo, negaron que

${ }^{6}$ La Nación, 12 de febrero de 2003.

${ }^{7}$ La Nación, 11 de febrero de 2003; En el informe del Observatorio pyмі (2003) "La situación de las pequeñas y medianas industrias argentinas antes y después de la devaluación”, la UIA ponderaba el aumento de ventas, producción y nivel de ocupación de las PYMEs. Según lo expresado en este documento, los pequeños capitales reaccionaron positivamente más rápido que las grandes empresas por no contar con endeudamiento externo.

${ }^{8}$ Clarín, 8 de mayo de 2003. 
pudiera afectar la solidez fiscal y apostaron a que la medida repercutiera en una baja de costos del financiamiento externo (Constant, 2015).

Otra cuestión que apareció (y permanecerá) durante el periodo observado fue la salarial. La tónica de la UiA era pactar aumentos salariales, en negociación con la Confederación General del Trabajo (CGT), que significaran cierta recuperación de los sueldos corroídos por la inflación y la devaluación; pero, a la vez, fijar topes para que no se "desbordaran" los reclamos futuros y para intentar atar los aumentos a la productividad de cada sector. Desde mediados de la década de 1970, la baja salarial constituyó una nueva fuente de compensación de los capitales de baja productividad radicados en Argentina. La acción política de la UiA se encaminaba a impulsar políticas que sostengan dicha forma de compensación. ${ }^{9}$

Vinculado al costo de la fuerza de trabajo, la uia elaboró en 2006 un proyecto de modificación de la ley de riesgo de trabajo. Esta tenía como ejes anular la doble indemnización, sancionar un tope indemnizatorio para aquellos accidentes producidos en los viajes de ida o vuelta al lugar de trabajo, con el argumento de que constituían un sobrecosto e inhibían la contratación de empleados. ${ }^{10}$ Asimismo instaba a que los comités integrados por dirigentes gremiales y ejecutivos no tuvieran facultades de decisión sobre las empresas. La ley fue sancionada finalmente en 2012, con la incorporación de muchas de las propuestas de los capitalistas.

La solicitud de créditos, inversión en infraestructura y programas a favor de las PYMEs también constituyeron reclamos constantes de la entidad para reducir los costos de producción y así mejorar la competitividad. La "necesidad" de recrear un empresariado nacional con perspectiva de inserción internacional fue una de las razones esgrimidas por Pagani (dueño de Arcor) en calidad de vocero de la corporación, para justificar la intervención estatal mediante las medidas mencionadas. La supuesta mentalidad liberal de los grandes capitales, muy difundida en la producción científica y política, choca contra las necesidades de reproducción de un capitalismo débil que se articu-

${ }^{9}$ Durante la gestión estatal estudiada se asistió a un mejoramiento salarial desigual. Los que más se beneficiaron fueron aquellos sectores registrados de la industria, que llegaron a alcanzar en 2012 casi los niveles de 1974 (en términos de salario directo, con un notable deterioro del salario indirecto), mientras que la mayoría de los asalariados no registrados o de industrias como la gastronómica, hotelera y de la construcción apenas alcanzó los niveles salariales del menemismo (Kornblihtt, Seiffer, Villanova, 2014).

${ }^{10}$ Hecho en Argentina, 2005. 
la en torno a las transferencias que realiza el Estado en cuanto capital social, a los capitales individuales.

\section{Aliados frente a "el campo"}

El llamado "conflicto del campo" marcó una ruptura de un sector de los capitalistas con el gobierno nacional, así como reforzó los vínculos con otros, especialmente con la UIA y la CGE. ${ }^{11}$

La disputa comenzó en marzo de 2008, a pocos meses de la asunción de Cristina Fernández de Kirchner como presidenta, con el anuncio de la implementación de la Resolución 125 por parte del ministro de Economía Martín Lousteau. Con el argumento del control de la inflación y la sojización, ante el alza de los precios de la soja, se elevarían las retenciones; estas ascenderían a $41 \%$ para la soja y se establecería un sistema prefijado de retenciones móviles, que subirían o bajarían las alícuotas según evolucionaran los precios. Al pasar los 610 dólares, las retenciones serían de $95 \%$ sobre la parte que excediera a ese precio.

El intento de incrementar las retenciones buscaba aumentar los ingresos estatales, necesarios para sostener el entramado de transferencias directas e indirectas al capital. Los gastos estatales tienen por fin garantizar la acumulación de capital y, en lo posible, la legitimación del sistema (O'Connor, 1981). Los gastos que apuntan a una acumulación privada rentable pueden destinarse a inversión social (proyectos que aumentan los beneficios del capital individual) o a consumo social (proyectos que disminuyen el costo de reproducción de la fuerza de trabajo). En este sentido, las diferentes formas de asistencia social y las tarifas de servicios subsidiadas, a la vez que permitían un mejoramiento relativo de las condiciones de vida, tenían como objetivo principal sostener una parte de la reproducción de la fuerza de trabajo en términos materiales y subjetivos, propiciando cierta armonía social.

${ }^{11}$ La Confederación General Económica es una institución nacida en 1952 que ha nucleado pequeños y medianos empresarios argentinos, bajo un programa económico orientado al mercado-internismo. Ha oscilado entre la confrontación y la fusión con la UIA, como durante el tercer gobierno peronista (1973-1976). Se diferencian porque mientras la UIA representa tanto a grandes empresarios a escala nacional, como a pequeños y medianos, la CGE incorpora sólo a capitales de menor tamaño. 
Inmediatamente, las principales corporaciones de capitalistas y terratenientes agropecuarios (Confederaciones Rurales Argentinas; Confederación de Asociaciones Rurales de Buenos Aires y La Pampa, Sociedad Rural Argentina y Federación Agraria Argentina) reaccionaron decretando un plan de lucha que incluía el cese de la comercialización, asambleas y marchas de protesta por 24 horas (Trento, 2017).

Varios sectores económicos que verían menguados sus ingresos respondieron de forma positiva a la convocatoria sobre el paro general. ${ }^{12}$ Esta medida de fuerza produjo nuevos alineamientos, particularmente en las grandes cámaras empresarias: mientras en el coloquio del Instituto para el Desarrollo Empresarial de la Argentina (IDEA) se defendían las retenciones, la Coordinadora de Industrias de Productos Alimenticios (Copal), integrante de la UIA, formulaba, aunque de manera tardía, sus reparos sobre la Resolución 125 y se pronunciaba en disidencia respecto de la posición oficial de la UiA. ${ }^{13}$

La dirigencia de la Unión Industrial Argentina se reunió con Cristina Fernández de Kirchner el mismo día del anuncio de las medidas, en señal de apoyo. La entidad presentó su "Propuesta integradora para un proyecto de desarrollo", que recogía las conclusiones de las últimas dos conferencias industriales. El trabajo operaba como una intervención política general y de formación de sentido ante otros sujetos sociales, antes que como una acción con propósitos inmediatos. Planteaba el objetivo de transformar el "crecimiento" argentino de los últimos cinco años en "desarrollo", e identificaba metas cuantitativas para el año 2016 y un conjunto de condiciones para lograrlas (inversión, financiamiento, marco macroeconómico, infraestructura, reformas educativas, condiciones de empleo y relaciones laborales).

El kirchnerismo, en sintonía con los capitalistas industriales, convirtió en ley la iniciativa que otorgaba descuentos impositivos a las inversiones en actividades industriales y en obras de infraestructura y anunció que estaba dando los últimos retoques a un paquete de medidas con el que buscaría apuntalar avarios sectores productivos. Los beneficiados serían los autopar-

${ }^{12}$ Federación Argentina de Contratistas de Maquinaria Agrícola; Bolsas de Cereales de Bahía Blanca, Buenos Aires, Córdoba y Entre Ríos; Bolsas de Comercio de Rosario y Santa Fe; Federación de Acopiadores de Granos.

${ }^{13}$ En los debates de comisión del Congreso, sus dirigentes expresaron que "se paguen los precios plenos a los productores y para que el sistema de retenciones móviles se adecue a límites razonables para que los sectores productivos no se vean afectados en su rentabilidad". La Nación, 26 de junio de 2008. 
tistas, los criaderos de pollos, los textiles y la exportación de servicios. Las políticas incluían promoción fiscal, protección ante el avance de las importaciones y acceso al financiamiento.

La UIA adoptó una posición cada vez más "militante". De hecho, Lascurain pidió que el campo levantara las medidas. El día 2 de abril, la presidenta dio un fuerte discurso, aplaudida por el presidente de la UIA, Lascurain, el de la Asociación de Bancos Argentinos (ADEBA), Jorge Brito del Banco Macro, y el de FiAT (Cristiano Rattazzi) situados en primera fila, escena que se reiteró en cada convocatoria del gobierno para mostrar su fuerza frente a la alianza articulada en torno a las corporaciones agropecuarias. El acuerdo con el gobierno se mantuvo inamovible, aunque la entidad se negó a firmar el Pacto del Bicentenario, un pacto social en respaldo al modelo que el gobierno promovía con gran ímpetu, por la falta de resolución del conflicto con el campo $y$, en consecuencia, la ausencia de un actor central de la economía argentina (Wyczykier, 2015). Quizás fue la tensión entre el actuar de una política de clase, que suponía cerrar filas con los empresarios agropecuarios, y una política sectorial, que suponía apoyar al gobierno que los favoreció con su fomento a la industria, lo que anuló la firma del Pacto.

La determinación económica del apoyo de la agrupación fue necesario para que se incrementara la fuente de riquezas (renta de la tierra) que el Estado capturaba en un momento de alza de precios agropecuarios y que así existieran mayores recursos para transferir a los sectores no agrícolas. Atravesados por tensiones internas y con el gobierno, reflejadas en las oscilaciones en sus posiciones, los capitalistas individuales nucleados en la entidad necesitaban dichas transferencias para poder reproducirse, y esa forma de compensación de su falta de competitividad explica la recuperación de este sector durante el periodo analizado. ${ }^{14}$

\section{El quiebre interno}

Las divergencias entre las distintas fracciones de la burguesía que se manifestaron durante el conflicto del campo se profundizaron -aunque no inmedia-

\footnotetext{
${ }^{14}$ Asimismo, de manera más directa, la intervención de la UIA tuvo por fin destrabar un conflicto que obstaculizaba las cadenas productivas de la industria alimentaria, con fuerte peso en la entidad (Coviello, 2014).
} 
tamente- y comenzaron a coagular en núcleos de acción más o menos estables. Mientras tanto, la UiA planteaba sus propuestas para capear la crisis y criticaba ciertas medidas, pero sin separarse del gobierno.

La crisis que se inició en 2008 sin duda catalizó los reclamos de los empresarios. No obstante, las posiciones, no fueron lineales, sino que oscilaron conforme al desarrollo de la crisis internacional. En un primer momento, la UIA pidió prudencia por el aumento del dólar, argumentando que podría generar una escalada inflacionaria. Ante la devaluación del real en Brasil y de la moneda chilena, Lascurain (presidente de la UIA) sostuvo en un principio que "no podemos seguir la devaluación abrupta de Brasil, ni la de Chile. Tenemos realidades distintas". ${ }^{15}$ El problema era que la devaluación de Brasil, principal socio comercial de Argentina, podía generar una invasión de productos de ese origen y la consecuente quiebra de empresas nacionales, incapaces de competir con las del país vecino. Por este motivo, las posiciones de la UiA fueron virando, hasta recalar en un pedido de devaluación brusca del peso, a pesar de los efectos inflacionarios que esta conllevara.

La respuesta de la presidenta a los reclamos de la entidad empresarial provocó encontronazos. Por un lado, Cristina Fernández sostuvo ante la UiA la incompatibilidad de la devaluación con la inflación. Esa declaración abrió las discusiones acerca de la forma en que se debía efectuar la devaluación del peso: de forma gradual, opinaba el gobierno; brusca, sostenía la UIA. No parecen haber existido debates de fondo acerca de la necesidad de devaluar, pero una devaluación brusca implicaba un estallido inflacionario, muy inconveniente en plena campaña electoral. Por su parte, para la corporación empresarial primaba la urgencia de la situación económica de sus socios por sobre los posibles coletazos políticos de la devaluación. La prioridad era frenar la oleada de importaciones de mercancías, que no tenía cabida en un mercado en recesión. ${ }^{16}$

De Mendiguren se mostró más sereno, lo que encuentra explicación en que gozó de políticas hechas a la medida de la industria en la que acumulaba. Se sancionaron impuestos a bienes textiles, juguetes, etc., que funcionaban como barrera de contención a las importaciones (Murua y Mussi, 2008).

${ }^{15}$ La Nación, 10 de octubre de 2008.

${ }^{16}$ Lascurain sugirió que se apliquen "las herramientas necesarias para no sufrir daños por el desvío de importaciones que tenían por destino otros mercados que se cayeron, y entonces quieren venir a la Argentina". La Nación, 8 de octubre de 2008. 
El artículo 34 del presupuesto 2009 disparó las críticas de la UiA. Dicho artículo disponía eximir del pago del derecho de importación a las mercaderías, nuevas o usadas, destinadas a obras de infraestructura energética. El beneficio contemplaba a aquellas obras referidas a la generación, el transporte y la distribución de energía eléctrica; la prospección, exploración, producción y explotación de gas y petróleo; la constitución de nuevas refinerías de petróleo y la ampliación de las existentes; y el transporte, el almacenaje y la distribución de hidrocarburos. La oposición de Lascurain no se hizo esperar; sostuvo que: "el proyecto de artículo que nos ocupa ha generado gran preocupación en varios sectores industriales representados en nuestra entidad, ya que verán directamente afectada su competitividad frente a proveedores extranjeros, tanto por la exención del arancel externo como por la competencia de productos usados. ${ }^{17}$

Esta medida, perjudicial para los pequeños y medianos empresarios productores de insumos destinados al sector, favoreció a otra fracción de la burguesía no representada por la UIA: las compañías petroleras YPF y PanAmerican Energy, y los empresarios de este rubro (José Luis Manzano, Cristóbal López y Lázaro Báez). También se verían beneficiados con la compra de insumos a bajo precio los capitales dedicados a la generación y transporte eléctrico, como Pampa Holding y Electroingeniería S. A., además de las empresas Edenor y Edesur.

Solucionar los problemas energéticos arrastrados desde tiempo atrás requería, por un lado, medidas que permitieran que el sector importara tecnología adecuada a bajo costo en medio de una devaluación y, como contrapartida, conllevaba el perjuicio para muchos industriales nacionales de la rama: dado su retraso tecnológico, estos no podrían competir con los bienes importados. En este sentido, la UiA encuadró su reclamo en una violación del acuerdo conocido como "Compre nacional", pactado con la presidenta para favorecer la demanda de bienes nacionales. Según un comunicado de la organización, el artículo 24 abría la importación a un universo muy vasto e impredecible de productos que afectarían a los proveedores de insumos, cuyo único mercado eran las obras de infraestructura pública y privada. ${ }^{18}$ "El Gobierno Nacional, en el proyecto de Ley de Presupuesto del año 2009 presentada al Congreso, incluyó en su artículo 34, una cláusula por la cual se exime del

\footnotetext{
${ }^{17}$ www.lanacion.com.ar, 28 de septiembre de 2008.

${ }^{18}$ www.uia.org.ar, 23 de septiembre de 2008.
} 
pago del derecho de importación a las mercaderías, nuevas o usadas, destinadas a obras de infraestructura" en el sector energético. Dichas obras deberán ser declaradas "como Proyecto Crítico por la SECRETARIA DE ENERgIA DEL MINISTERIO DE PLANIFICACION FEDERAL, INVERSION PUBLICA Y SERVICIOS”. Lo arriba trascrito genera gran preocupación al conjunto de la industria nacional, por cuanto se están creando condiciones desfavorables para la competitividad de nuestra producción a través de la creación de mecanismos de excepcionalidad, afectando muy seriamente la producción local. ${ }^{19}$

La respuesta de la UIA ante medidas que desfavorecían a la mayoría de las empresas que representaba fue dejar sin efecto el tan mentado "Pacto social", un acuerdo entre corporaciones de capitalistas y sindicatos obreros en el que se comprometerían, por un lado, a evitar despidos y suspensiones $y$, por el otro, a moderar los reclamos salariales. Comenzaron los capitales de la industria automotriz y autopartista, y luego fueron cada vez más los que recurrieron a despidos y suspensiones de turnos.

Otro hito del periodo fue la estatización de YPF. Aunque el discurso de nacionalización de un capital privado pueda suponer que los capitalistas individuales den señales de alerta, no fue lo que ocurrió. ${ }^{20}$ Más allá del pedido de "prudencia jurídica", la entidad destacó que la estatización de la empresa petrolera permitiría "reducir la dependencia de hidrocarburos importados", con el fin de lograr la "sustentabilidad del crecimiento económico durante décadas" ${ }^{21}$ Lo que en realidad estaba en juego -y beneficiaba a los capitalistasera la transferencia de riqueza por los precios preferenciales de los combustibles, que redundaban en menores costos de producción (Ruiz y Bil, 2012).

El establecimiento del cepo al dólar en 2012 significó un nuevo desacuerdo de la UIA con el gobierno. ${ }^{22} \mathrm{El}$ titular de la corporación, Ignacio de Mendiguren, declaró que "los controles sobre la compra de dólares son exagerados" y generan un clima de crisis que no se corresponde con la realidad. El informe de la UIA también reconoce que las restricciones a las compras externas, en forma contradictoria, no generaron un proceso de sustitución de importaciones. $^{23}$

${ }^{19}$ www.uia.org.ar, 23 de septiembre de 2008.

${ }^{20}$ Entre otras cuestiones, porque se trató de una compra -y no expropiación-que beneficiaba a capitales que querían deshacerse de sus acciones.

${ }^{21}$ La Nación, 2 de mayo de 2012.

22 El "cepo" fue una medida de control de comercialización de monedas extranjeras.

${ }^{23}$ Clarín, 11 de julio de 2012. 
La continuidad de las condiciones económicas recesivas culminó con la oficialización de un núcleo de oposición dentro del empresariado: el Foro de Convergencia. Se trató de un agrupamiento que vio la luz durante el verano de 2014, impulsado por la Comisión de Enlace conformada durante el conflicto del campo (integrada por la Sociedad Rural Argentina; la Federación Agraria Argentina; Confederaciones Rurales Argentinas, y Coninagro), del que también participaron los grupos de la Asociación Argentina de Consorcios Regionales de Experimentación Agrícola (AACREA), la Asociación de Bancos de Argentina (ABA), la Asociación Empresaria Argentina (AEA), American Chamber of Commerce; Instituto para el Desarrollo Empresarial de la Argentina (IDEA); la Fundación Mediterránea, la Confederación de Empresarios del Transporte. y la Cámara de Importadores de la República Argentina (CIRA). Asistieron también dirigentes de la UIA, como Cristiano Ratazzi y Luis Betnaza, ${ }^{24}$ pero lo hicieron a título personal.

La entidad mantuvo una relación distante con el Foro, apareciendo como firmante y luego alejándose. Muchos de sus socios habrían constreñido a la dirección a retirar a la UiA del flamante grupo. ${ }^{25}$

El Foro proponía un plan económico consistente en bajar la inflación sin controles de precios; la instauración de regulaciones jurídicas que habilitaran el aliento de las inversiones de infraestructura en energía, transporte y comunicaciones (mediante la liberalización de las tarifas); reducir los impuestos sobre las empresas; eliminar los "tipos de cambio diferenciales" y las retenciones, lo que implicaba, como consecuencia, bajar los gastos estatales. ${ }^{26}$

La dirigencia de la UIA se concentró en darle impulso al G-6, un agrupamiento integrado por la ADEBA, la Cámara de la Construcción, la Bolsa de Comercio, la Sociedad Rural Argentina (que aparece en ambos núcleos) y la Cámara Argentina de Comercio. El objetivo era diferenciarse de la propuesta "ajustadora" y decididamente antikirchnerista del Foro, aunque las últimas intervenciones de sus miembros dan cuenta de más similitudes que diferen-

${ }^{24}$ Techint, representada por Betnaza, había protagonizado un enfrentamiento con el gobierno luego de años de apoyo. La disputa entre el kirchnerismo y la familia Rocca se inició cuando al conglomerado de empresas le empieza a ir relativamente mal en la Argentina y comienza a buscar nuevos horizontes, por fuera del espacio nacional, que le permitieran ampliar su rentabilidad (Mussi, 2013).

${ }^{25}$ En la actualidad, la UiA figura como miembro en la página institucional del Foro de Convergencia Empresarial.

${ }^{26}$ La Nación, 16 de mayo de 2014. 
cias en sus demandas. Desde la devaluación de inicios del año 2014, la uia ha mostrado gran preocupación por las paritarias, y demandado que se contengan los pedidos de los sindicatos. Su argumento es el de siempre: moderar los reclamos salariales como una forma de defender el empleo. Sin embargo, sus dirigentes se opusieron a los intentos de frenar despidos, así como al restablecimiento del régimen de doble indemnización.

Héctor Méndez, presidente de la entidad, sostuvo inclusive la necesidad de recortar los subsidios y achicar los gastos del Estado. ${ }^{27}$ En el mismo sentido se expresó la ADEBA, que apoyó el aumento de tarifas de gas y agua impulsada por el gobierno, y exigió que alcanzara también a la electricidad y al transporte.

Una de las últimas desavenencias del gobierno con la UIA, que quedó solo en un acalorado debate, se produjo a propósito de la ley de abastecimiento, en septiembre de 2014. El alto nivel de inflación que corroía los salarios era atribuido por el gobierno nacional a los empresarios especulativos que fijaban los precios de los bienes de consumo en busca de ganancias extraordinarias. Para combatirla, además del programa Precios cuidados, promovió la sanción de dicha norma. "Este paquete de leyes es para dotar al Estado de instrumentos para defender a los consumidores. Defender a los más débiles de los incumplimientos". ${ }^{28}$ La mayoría de las corporaciones de capitalistas se opusieron a la ley; el ángulo privilegiado fue defenderse contra el intervencionismo del gobierno. La UIA manifestó, a través de un comunicado, que la norma "potencia la intervención discrecional del Estado en la economía y en las empresas, confiando márgenes de utilidad, niveles de stock, precios, volúmenes de producción y canales de distribución, entre otros mecanismos de intervención" ${ }^{29}$

Mientras la entidad, pese a su tono cada vez más intransigente, no se alejaba del gobierno, algunos de sus socios se pasaron a sectores opositores. Las elecciones presidenciales de 2015 profundizaron las divergencias internas. Los tres candidatos más convocantes -Mauricio Macri (opositor, liberal), Daniel Scioli (oficialista) y Sergio Massa (opositor, centroderecha)- hallaron apoyos entre los miembros de la corporación. Los que se apartaron del gobierno y se ubicaron junto a Macri fueron los integrantes de la Asociación

${ }^{27}$ Cronista Comercial, 3 de junio de 2014.

${ }^{28}$ www.uia.org.ar (16 de septiembre de 2014).

${ }^{29}$ www.uia.org.ar (16 de septiembre de 2014). 
Empresaria Argentina (AEA), grandes capitales nacionales que tienen más margen de acción frente al Estado; además de exdirigentes como De Mendiguren, que se inclinaron por la lista encabezada por Sergio Massa. Quienes respaldaron públicamente al candidato oficialista fueron Osvaldo Rial (Hermetal) y Guillermo Moretti (Federación de Industriales de Santa Fe). La entidad como tal no se pronunció abiertamente contra el gobierno de Cristina Fernández de Kirchner, aunque el resultado de las últimas elecciones internas demostró un cierto alejamiento. Tal como lo estipula el pacto de alternancia entre listas, asumió la presidencia Adrián Kaufmann Brea (Arcor). Las reservas de algunos miembros no pudieron revocar el ascenso de los dirigentes que expresaban, en el interior de la corporación, los intereses de los capitales más concentrados alineados con Macri. No obstante, la incertidumbre ante el resultado de las elecciones presidenciales parece haber obligado a la UIA a actuar con cautela.

\section{REFLEXIONES FINALES}

Luego de un recorrido sistemático por las intervenciones políticas de la UIA frente a los gobiernos kirchneristas, podemos dar cuenta de algunas características de las mismas.

La entidad fue una de las bases de apoyo del gobierno. Más allá de sus demandas, no constituyó un núcleo opositor durante la mayor parte del mandato de Néstor y Cristina Kirchner. Las determinaciones económicas que permiten explicar el vínculo radican en que el país se encontraba en un momento de fuerte expansión de la principal riqueza que sostiene al capitalismo débil argentino: la renta de la tierra. El aumento internacional de los precios agropecuarios posibilitó que se expandieran los ingresos de divisas que, mediante diversos mecanismos -como el tipo de cambio y los impuestos directos- el Estado pudo capturar y redirigir a otros sectores sociales.

Los capitales industriales que componen la UIA estuvieron entre los principales beneficiarios de las transferencias de riquezas. Mediante la devaluación, barreras arancelarias y subvenciones, el Estado recreó un marco propicio para la acumulación de sus capitales, protegidos de la competencia extranjera con ingentes subsidios directos e indirectos (tarifas de servicios subvencionadas y créditos a tasas inferiores a las de la inflación, entre otros programas de fomento empresarial) y costos laborales con mayor poder ad- 
quisitivo para generar demanda interna, pero a su vez relativamente bajos a escala internacional. Sus demandas se dirigieron a mantener vigentes dichas condiciones, indispensables para la reproducción de sus capitales.

Durante el kirchnerismo el Estado, en cuanto representante del capital social, lejos de enfrentar a las fracciones más concentradas del capital caracterizadas en el debate político-intelectual como antiindustriales y antipopulares del capital, garantizó su acumulación.

El trabajo pone en tensión aquellas interpretaciones clásicas, muchas de ellas matizadas pero aún vigentes en la actualidad, que sostienen que la UIA ha defendido históricamente un programa liberal clásico, o antiindustrial-cortoplacista, y que en consecuencia ha atentado contra el despliegue de las potencias del capitalismo nacional. Como vimos, las debilidades de sus socios le impidieron sostener una política de liberalización total del mercado y la apertura indiscriminada de la economía a la competencia internacional. Sus capitales requerían transferencias estatales y la protección del mercado interno para poder reproducirse. Aun cuando contaban en su interior con capitales concentrados nacionales y transnacionales, no se observa que pugnaran por la liberalización de la economía.

Esto es así porque se reproducen mayormente en el mercado interno, no utilizan a Argentina como plataforma de exportación, con lo cual necesitan que se mantengan las condiciones para vender en el mercado interno y apropiarse de riquezas emanadas de la renta de la tierra. En lo sustancial, llevan adelante una acción política igual a la de los capitales supuestamente portadores de las virtudes de una burguesía nacional. Si esto no ha redundado en que Argentina cambie sus particularidades es porque la política de los capitalistas se manifiesta impotente contra la fuerza con que el capitalismo mundial impone el lugar que ocupa nuestro país.

\section{LISTA DE REFERENCIAS}

Acuña, C. H. (1995). Política y economía en la Argentina de los 90 (o por qué el futuro ya no es lo que solía ser). En C. H. Acuña (comp.), La nueva matriz política argentina. Buenos Aires: Editorial Nueva Visión.

Acuña, C. H. (1996). Las contradicciones de la burguesía en el centro de la lucha entre el autoritarismo y la democracia (1955-1983). Realidad Económica, 138, 18-48. 
Altvater, E. (1976). Estado y capitalismo. Notas sobre algunos problemas del intervencionismo estatal. Cuadernos políticos, 9, 9-30.

Azpiazu, D. y Schorr, M. (2010). Hecho en Argentina. Industria y Economía 1976-2007. Buenos Aires: Siglo XXI Editores.

Basualdo, E. M. (2006). Estudios de historia económica argentina. Desde mediados del siglo $\mathrm{xx}$ a la actualidad. Buenos Aires: Siglo XIX.

Baudino, V. (2012). La estrategia de la UIA 1966-1976. (Tesis doctoral inédita). Facultad de Filosofía y Letras, Universidad de Buenos Aires, Argentina.

Baudino, V. (2017). Estado y régimen político en Latinoamérica contemporánea. Revista Theomai, 35, 187-200. Recuperado de http://revista-theomai.unq.edu.ar/ NUMERO_35/Index.htm

Beltrán, G. (2006). Acción empresaria e ideología. La génesis de las reformas estructurales. En A. Pucciarelli (coord.), Los años de Alfonsín ¿El poder de la democracia o la democracia del poder? (pp. 199-243). Buenos Aires: Siglo XXI Editores.

Brennan, J. y Rougier, M. (2013). Perón y la burguesía argentina. El proyecto de un capitalismo nacional y sus límites (1946-1976). Buenos Aires: Lenguaje Claro.

Cantamutto, F. (2017). Disputa por la hegemonía: el kirchnerismo en la Argentina. Realidad Económica, 311, 9-39. Recuperado de http://www.iade.org.ar/articulos/ disputa-por-la-hegemonia-el-kirchnerismo-en-la-argentina

Castellani, A. y Gaggero, A. (2018). La relación entre el Estado y la elite económica. En A. Pucciarelli y A. Castellani, Los años del kirchnerismo: La disputa hegemónica tras la crisis del orden neoliberal. Buenos Aires: Siglo XXI.

Constant, J. (2015). La cancelación de la deuda con el FMI. (Tesis de licenciatura inédita). Facultad de Humanidades y Ciencias de la Educación-Universidad Nacional de La Plata, Argentina.

Coviello, R. (2014). El posicionamiento de la Unión Industrial Argentina durante el conflicto agropecuario de 2008. Realidad Económica, 282, 125-151. Recuperado de http://www.iade.org.ar/articulos/el-posicionamiento-de-la-union-industrial-argentina-durante-el-conflicto-agropecuario-de

Cúneo, D. (1967). Comportamiento y crisis de la clase empresaria. Buenos Aires: Pleamar.

Dossi, M. (2009). La acción colectiva de la Unión Industrial Argentina en el periodo 1989-2002. Un análisis desde su dinámica organizativa-institucional. Documentos de Investigación Social, 10.

Eskenazi, M. (2009). El espectro de la dolarización: discutiendo las interpretaciones sobre la disputa interburguesa en el origen de la crisis de la convertibilidad. En A. Piva, Argentina en pedazos. Luchas sociales y conflictos interburgueses en la crisis de la convertibilidad. Buenos Aires: Peña Lillo. 
Fernández, C. (2002). El análisis de contenido como ayuda metodológica para la investigación. Revista de Ciencias Sociales, 96, 35-53.

Fitzsimons, A. (2013). Producción, relaciones sociales y valor: una crítica a la teoría del patrón de acumulación basado en la valorización financiera. Razón y Revolución, 24, 85-103. Recuperado de http://revistaryr.org.ar/index.php/RyR/article/ view/6/6

Freels, J. (1970): El sector industrial en la política nacional. Buenos Aires: Eudeba.

Gaggero, A. y Wainer, A. (2009). Burguesía nacional-Crisis de la convertibilidad: el rol de la UIA y su estrategia para el (tipo de) cambio. Realidad Económica, 204, 1441. Recuperado de http://www.iade.org.ar/noticias/burguesia-nacional-crisis-dela-convertibilidad-el-rol-de-la-uia-y-su-estrategia-para-el

Gaggero, A., Schorr, M. y Wainer, A. (2014). Restricción eterna: el poder económico durante el kirchnerismo. Buenos Aires: Futuro Anterior.

Grimaldi, N. (2014). Análisis comparativo de las corporaciones empresariales argentinas y venezolanas entre el 2002 y el 2006. Ponencia presentada en las VIII Jornadas de Sociología, unlp, Ensenada, Argentina.

Ímaz, J. de (1965). Los que mandan. Buenos Aires: Eudeba.

Iñigo Carrera, J. (2003). El capital: razón histórica, sujeto revolucionario y conciencia. Buenos Aires: Ediciones Cooperativas.

Iñigo Carrera, J. (2007). La formación económica de la sociedad argentina. Buenos Aires: Imago Mundi.

Kornblihtt, J., Seiffer, T. y Villanova, N. (2014). De la caída relativa a la caída absoluta del salario real en la Argentina (1950-2013). Revista Científica Guillermo de Ockham, 12(2), 41-50. Dor: https://doi.org/10.21500/22563202.61

Kornblihtt, J., Seiffer, T. y Mussi, E. (2016). Las alternativas al neoliberalismo como forma de reproducir la particularidad del capital en América del Sur. Pensamiento al margen, 4.

Marx, K. (2004). El capital. Buenos Aires: Siglo XXI.

Murua, C. y Mussi, E. (2008). sos: Industria Argentina. La producción y el empleo de cara a la crisis. El Aromo, 45.

Mussi, E. (2013). El conflicto entre los gobiernos kirchneristas y el grupo Techint (2000-2011). Un estudio de la rentabilidad del grupo económico y su expresión política. Ponencia presentada en las X Jornadas de Sociología, Facultad de Ciencias Sociales-Universidad de Buenos Aires, Argentina.

Niosi, J. (1974). Los empresarios y el Estado argentino (1955-1969). Buenos Aires: Siglo XXI Editores.

O’Connor, J. (1981). La crisis fiscal del Estado. Barcelona: Ediciones 62. 
O’Donnell, G. (1982). El Estado burocrático-autoritario. Triunfos, derrotas y crisis. Buenos Aires: Editorial Belgrano.

Peña Vera, T. y Pirela Morillo, J. (2007). La complejidad del análisis documental. Información, Cultura y Sociedad, 16, 55-81.

Piva, A. (2019). Los límites de una estrategia contradictoria. La dinámica económico-política del kirchnerismo (2003-2015). En H. Ouviña y M. Thwaites Rey (comps.), Estados en disputa. Auge y fractura del ciclo de impugnación al neoliberalismo en América Latina. Buenos Aires: Clacso.

Porta, F., Santarcágelo, J. y Schteingart, D. (2018). Un proyecto político con objetivos económicos. Los límites de la estrategia kirchnerista. En A. Pucciarelli y A. Castellani, Los años del kirchnerismo: La disputa hegemónica tras la crisis del orden neoliberal. Buenos Aires: Siglo XXI.

Ruiz, B. F. y Bil, D. (2012). Aproximación a la medición de la renta petrolera argentina y sus mecanismos de transferencia (1963 a la actualidad). V Jornadas de Economía Crítica. La Crisis Global como Crisis del Pensamiento Económico, Facultad de Ciencias Económicas-Universidad de Buenos Aires, Argentina.

Schteingart, D. (2011). La concepción del desarrollo de la Unión Industrial Argentina (2000-2010). Documentos de Investigación Social, 17.

Schvarzer, J. (1991). Empresarios del pasado. La Unión Industrial Argentina. Buenos Aires: Imago Mundi.

Thwaites Rey, M. (2010). Después de la globalización neoliberal. ¿Qué Estado en América Latina? Cuadernos del Pensamiento Crítico Latinoamericano, 32.

Trento, N. P. (2017). El paro agrario del 2008 y la especificidad de la acumulación de capital en la Argentina. Revista de Economía Crítica, 23, 43-59.

Wyczykier, G. (2015). Las disputas por el desarrollo: narrativas y posicionamientos de los empresarios de la Unión Industrial Argentina en las coyunturas políticas de 2008. Temas y Debates, 30, 109-134. DoI: https://doi.org/10.35305/tyd.v0i30.324

Wyczykier, G. y Anigstein, C. (2014). Las disputas por el excedente y la perspectiva del desarrollo: trabajadores y empresarios ante el Proyecto de Participación en las Ganancias Empresarias en la Argentina reciente. Revue Tiers-Monde, 220, 201-219. Recuperado de https://www.cairn.info/revue-tiers-monde-2014-4-page-201.htm 


\section{OTRAS FUENTES}

\section{Hemerografía}

La Nación.

Cronista Comercial.

Clarin.

Mercado.

Estimados Mensual Industrial (INDEC).

Informes del Observatorio (РYMI).

Hecho en Argentina, UIA. 